\title{
Incentive Mechanism for Product Quality of Retailers Based on Platform-Based E- Commerce
}

\author{
Lei $\mathrm{Xu}^{1,2}$, Changyue Dong ${ }^{3}$, Chunyi $\mathrm{Ji}^{{ }^{*}}$ \\ ${ }^{1}$ School of Business, Jiangnan University, Wuxi, Jiangsu, China \\ ${ }^{2}$ Research Institute for Food Safety Risk Management, Jiangnan University, Wuxi, Jiangsu, China \\ ${ }^{3}$ School of Management, University of Science and Technology of China, Hefei, Anhui, China \\ *Corresponding Author.
}

\begin{abstract}
:
In order to explore the autonomous incentive mechanism of platform-based e-commerce to online retailers' products, a product quality incentive model based on deposit and commission management is established for single retailer single quality products, single retailer products at multiple quality levels and double-retailer different quality products in three cases. Comparative analysis of the equilibrium results in three cases reveals that the effectiveness of the incentive mechanism of platform discount in the first case depends on the deposit strategy of the platform and the influence of the unit cost of excellent and low-quality products. In the second case, the incentive mechanism of platform discount is completely effective. The platform price discount has a positive incentive effect on retailers. The online retailers' increasing the sales of high-quality products and reducing the sales of low-quality products improve the high-quality product rate in the market. In the third case, the effectiveness of the platform discount incentive mechanism is mainly affected by the unit cost of products.
\end{abstract}

Keywords: Retailer incentive, Product Quality, E-Commerce Platform

\section{INTRODUCTION}

High-quality development is the inevitable requirement of economic and social development, as well as the rapid development of online retailing. In recent years, online shopping has also encountered more and more problems in the rapid development, in which the problem of different degrees of product quality has become one of the bottlenecks in the development of e-commerce.

The quality of online shopping products is uncertain due to factors such as virtual trading 
platform, hidden merchant identity, and a wide range of commodity types, which makes the information cannot be accurately conveyed to consumers. According to statistics, about $20 \%$ of consumer complaints are about the quality of online shopping products. As the outbreak of the COVID-19, the market demand for epidemic prevention products has risen sharply, with a significant increase in the number of illegal cases and consumer complaints about the quality of epidemic prevention products, which has also pushed the problem of online shopping product quality to the forefront of public opinion. Frequent product quality problems have seriously hindered the healthy and orderly development of the online shopping market, and even affected the long-term development of the entire Internet retail industry.

The root of quality problems of online shopping products lies in information asymmetry and market uncertainty caused by network characteristics. Due to the wide range of online shopping platforms, the supervision mode dominated by government departments in the past needs to be improved. Therefore, how to make the platform effectively autonomous and motivate online retailers to improve product quality has become a very important issue.

At present, the quality incentive mechanism of e-commerce platform for online sellers mainly includes online reputation mechanism and quality credit mechanism. Resnick [1] first defined the meaning of online reputation mechanism. After that, a series of researches on how to use the reputation of merchants to motivate online sellers to improve product quality were gradually launched. Wang Dingwei [2] put forward a ranking auction mechanism based on the reputation of the merchants, which gives the reputable merchants the priority when bidding, and achieves the effect of encouraging the merchants to operate in good faith. Kang Wanglin et al. [3] designed a trusted third party principal mechanism based on collective reputation. Wang $\mathrm{Yu}$ et al. [4] found that the quality-first ranking of platforms has a better positive impact on retailers' improvement of product quality than the bidding ranking, and the quality-first ranking of medium-sized platforms can encourage some retailers to choose to provide high-quality products. Through the research, the internal defects of the online reputation mechanism are gradually discovered, that is, online sellers can cheat buyers through the behavior of "cash back by favorable comments" or click farming, which affects the authenticity of reputation evaluation. In this regard, how to improve and redesign the online reputation mechanism is discussed in some literatures. In order to effectively curb the online seller's "cash back by favorable comments", Zhao Hongxia et al. [5] designed a centralized reputation feedback mechanism by entrusting a third party. Xu et al. [6] proposed to establish a dynamic feedback incentive model to encourage online merchants to submit feedback information actively.

Compared with the online credit mechanism, the quality credit mechanism has more obvious effects. The common quality credit mechanism in online shopping supply chain is the 
trading deposit mechanism. Zhang E et al. [7] put forward the incentive mechanism of honest transaction considering the registration deposit and transaction guarantee fee, and verified the effectiveness of the incentive mechanism through simulation. In some studies, the optimization of deposit incentive contracts $[8,9]$ and revenue sharing contracts $[10,11]$ based on volume discounts is discussed. Zhang Shen et al. [12] further discussed the dual-channel supply chain pricing model to study the influence of the deduction rate of e-commerce platform on the coordinated pricing of supply chain. In view of the more complex trading situation, Sun Baowen et al.[13] put forward a dynamic trading deposit incentive mechanism considering the dynamic trading process in reality. Gui et al.[14] integrated pricing and quality strategies into the $\mathrm{B} 2 \mathrm{C}$ model and studied the quality assurance strategies of the monopoly B2C bilateral platforms. Song Han et al.[15] constructed a deposit incentive mechanism under the condition of incomplete trust, and concluded that this mechanism effectively encouraged buyers and sellers to improve the efficiency of initial online transactions. Gui Yunmiao et al.[16] analyzed the best quality efforts of decision-makers under three e-commerce modes: platform-based, self-operated and comprehensive e-commerce from the perspective of bilateral efforts of ecommerce platform and suppliers. Qin Xinghong et al.[17] designed an incentive contract of multilateral side payment for the coordination of online shopping service supply chain under the competitive environment of multiple service providers. Zhao et al.[18] studied the effectiveness of the fixed transaction fee strategy and the quality-based transaction fee strategy specified by the platform in the capacity sharing supply chain considering the impact of availability of production capacity, quality fluctuations and demand uncertainty. Subsequently, in some studies, the incentive content is extended to the competition of platform service resource allocation. For example, Zhao Hongxia et al.[19] studied the incentive of advertising resource allocation mechanism on the improvement of online merchants' product quality, providing a new idea for studying the incentive mechanism of online shopping supply chain.

Current research shows that an effective incentive mechanism can encourage online sellers to operate in good faith, but less involves the autonomy mechanism of the platform. In the management mode that the platform mainly relies on deposit and transaction fees, how does the online retailer's product quality decision change? Based on this, the discount incentive mechanism will be designed from the perspective of online shopping platform. Through the analysis of its effectiveness, the quality control problem of online shopping supply chain will be discussed in order to motivate online sellers to consciously reduce quality speculation and motivate them to improve product quality.

\section{QUALITY INCENTIVE OF E-COMMERCE PLATFORM UNDER THE CONDITION OF SINGLE RETAILER}




\subsection{Model and Hypothesis}

Suppose that a supply chain system consisting of an online retailer and an e-commerce platform faces a total consumer group of 1, and the holding value of goods $V$ of consumers is uniformly distributed on $[0,1]$.

When online retailers sell products through e-commerce platforms, they can choose to provide only one of high-quality products $\mathrm{H}$ or low-quality products $\mathrm{L}$, or provide both highand low-quality products at a unit $\operatorname{cost}$ of $c_{H}$ and ${ }^{c_{L}}$ respectively, without loss of generality, assuming that $c_{H}>c_{L}$. At the same time, retailers need to decide the price of the products they provide, assuming that the price per unit of high-quality products is $p_{H}$, and the price per unit of low-quality products is $p_{L}$.

E-commerce platforms adopt a free policy towards consumers and a charging policy towards online retailers. They will charge a fixed deposit ${ }^{c_{F}}$ when the retailers move in and a transaction fee per unit ${ }^{c_{f}}$ after their transactions. To encourage retailers to provide high-quality products, the platform will consider giving retailers who provide high-quality products a deposit discount $\alpha$ (that is, they only need to pay $\alpha c_{F}$ ) and a discount on unit transaction costs $\beta$ (that is, they only need to pay $\beta c_{f}$ per unit), where parameter $\alpha$ is defined as the coefficient of deposit discount $(0<\alpha<1)$ and $\beta$ as the coefficient of price discount $\left({ }^{0<\beta<1}\right)$, which are both incentives of e-commerce platforms for high-quality merchants.

In this paper, a logical hypothesis that conforms to the principles of economics is made: Under the decentralized decision-making, a dynamic game dominated by e-commerce platform is formed between the platform and online retailers, both of which make decisions according to their respective profit maximization. The game order of the two is: the platform first determines the deposit ${ }^{c_{F}}$, transaction cost ${ }^{c_{f}}$ and discounts $\alpha, \beta$ for retailers, and then the online retailers determine the product price ${ }^{p_{i}}$ based on the platform charging and maximization principle, $i \in\{H, L\}$.

\subsection{Optimal Decision Analysis of Platform and Retailer without Platform Discount}

2.2.1 Single retailer providing single quality products

Assume there is only a single retailer and only choose to sell products on that platform with 
either high quality or low quality. According to the product category $i \in\{H, L\}$ and price $p_{i}$ determined by the retailer, the market demand of this product is:

$$
q_{i}=1-p_{i}
$$

The profit functions of online retailers and e-commerce platforms are respectively:

$$
\begin{gathered}
\pi_{i}^{R}=\left(p_{i}-c_{i}\right) q_{i}-c_{F}-c_{f} q_{i}, \\
\pi_{i}^{P}=c_{F}+c_{f} q_{i} .
\end{gathered}
$$

Lemma 1. When the platform has no discount and the retailer provides only high-quality products:

(1) The retailer's optimal pricing is $p_{H 11}^{N^{*}}=\frac{c_{H}+3}{4}$, maximum profit is $\pi_{H 11}^{R N^{*}}=\frac{\left(1-c_{H}\right)^{2}}{16}-c_{F}$;

(2) The platform's optimal pricing is $c_{f 11}^{N^{*}}=\frac{1-c_{H}}{2}$, maximum profit is $\pi_{H 11}^{P N^{*}}=\frac{\left(1-c_{H}\right)^{2}}{8}+c_{F}$.

Proof: When retailers choose to provide high-quality products $\mathrm{H}$, their profit function is

$$
\pi_{H}^{R}=\left(p_{H}-c_{H}\right) q_{H}-c_{F}-c_{f} q_{H}
$$

The first derivative and the second derivative of the product price $p_{H}$ are

$$
\frac{d \pi_{H}^{R}}{d p_{H}}=1-2 p_{H}+c_{H}+c_{f}, \frac{d^{2} \pi_{H}^{R}}{d p_{H}^{2}}=-2 .
$$

Because the second derivative $<0$ shows that $\pi_{H}^{R}$ is a concave function of $p_{H}$, so the optimal pricing for online retailers with $\frac{d \pi_{H}^{R}}{d p_{H}}=0$ is

$$
p_{H}^{N^{*}}=\frac{1+c_{H}+c_{f}}{2}
$$

At this time, the profit of the platform is

$$
\pi_{H}^{P}=c_{F}+\frac{c_{f}}{2}\left(1-c_{H}-c_{f}\right)
$$


The first derivatives of $\pi_{H}^{P}$ for deposit $c_{F}$ and transaction cost $c_{f}$ are obtained respectively

$$
\frac{\partial \pi_{H}^{P}}{\partial c_{F}}=1, \frac{\partial \pi_{H}^{P}}{\partial c_{f}}=\frac{\left(1-c_{H}-2 c_{f}\right)}{2}
$$

And the second derivatives of $\pi_{H}^{P}$ for deposit $c_{F}$ and transaction cost $c_{f}$ are obtained respectively

$$
\frac{\partial^{2} \pi_{H}^{P}}{\partial c_{F}^{2}}=0, \frac{\partial^{2} \pi_{H}^{P}}{\partial c_{F} c_{f}}=0, \frac{\partial^{2} \pi_{H}^{P}}{\partial c_{f}^{2}}=-1, \frac{\partial^{2} \pi_{H}^{P}}{\partial c_{f} c_{F}}=0
$$

Thus, the Hessian matrix of $\pi_{H}^{P}$ is

$$
H\left(c_{F}, c_{f}\right)=\left[\begin{array}{cc}
0 & 0 \\
0 & -1
\end{array}\right]
$$

According to the above solution process, the optimal decision of the platform is not affected by the deposit $c_{F}$, and because the second derivative $\frac{\partial^{2} \pi_{H}^{P}}{\partial c_{f}^{2}}$ is less than 0 , if $\frac{\partial \pi_{H}^{P}}{\partial c_{f}}=0$, the optimal pricing of the platform is

$$
c_{f 11}^{N^{*}}=\frac{1-c_{H}}{2} .
$$

Substituting it into formula (6), the retailer's optimal pricing is

$$
p_{11}^{N^{*}}=\frac{1}{2}\left(1+c_{H}+\frac{1-c_{H}}{2}\right)=\frac{c_{H}+3}{4} .
$$

Maximum profit is

$$
\pi_{H 11}^{R N *}=\left(\frac{c_{H}+3}{4}-c_{H}-\frac{1-c_{H}}{2}\right)\left(1-\frac{c_{H}+3}{4}\right)-c_{F}=\frac{\left(1-c_{H}\right)^{2}}{16}-c_{F} .
$$

At this time, the maximum profit obtained by the platform is

$$
\pi_{H 11}^{P N^{*}}=c_{F}+\frac{1-c_{H}}{2}\left(1-\frac{c_{H}+3}{4}\right)=\frac{\left(1-c_{H}\right)^{2}}{8}+c_{F}
$$


Proven.

Lemma 2. When the platform has no discount and the retailer provides only low-quality products,

(1) The retailer's optimal pricing is $p_{L 11}^{N^{*}}=\frac{c_{L}+3}{4}$, maximum profit is $\pi_{L 11}^{R N^{*}}=\frac{\left(1-c_{L}\right)^{2}}{16}-c_{F}$;

(2) The platform's optimal pricing is $c_{f 11}^{N^{*}}=\frac{1-c_{L}}{2}$, maximum profit is $\pi_{L 11}^{P N^{*}}=\frac{\left(1-c_{L}\right)^{2}}{8}+c_{F}$.

Proof: Same as the proof principle of proposition 1, omitted here.

The comparison of the maximum profit under the retailer's two choices reveals that if both the retailer and the platform aim at profit maximization, the decision will be as shown in Proposition 1.

Proposition 1. $\pi_{L}^{R N^{*}}>\pi_{H}^{R N^{*}}, \pi_{L}^{P N^{*}}>\pi_{H}^{P N^{*}}$.

Proof: The comparison of the maximum profit under the retailer's two choices reveals that

$$
\pi_{L 11}^{P N^{*}}-\pi_{H 11}^{P N^{*}}=\frac{\left(1-c_{L}\right)^{2}}{8}+c_{F}-\frac{\left(1-c_{H}\right)^{2}}{8}-c_{F}=\frac{\left(2-c_{H}-c_{L}\right)\left(c_{H}-c_{L}\right)}{8} .
$$

As $c_{H}>c_{L}$, so $\pi_{L}^{R N^{*}}>\pi_{H}^{R N^{*}}$, and $\pi_{L}^{P N^{*}}>\pi_{H}^{P N^{*}}$. Proven.

Proposition 1 indicates that if the platform does not offer discounts and the retailer can only select a product with one quality level, the retailer and the platform will tend to offer lowquality products in their optimal decisions, which means that the e-commerce platform will not voluntarily adopt quality supervision or incentive measures based on self-interest and shortterm profit maximization under certain market conditions, and the online shopping market will be flooded with a large number of low-quality or problematic products.

For the convenience of analysis in the following, the optimal pricing of the platform under this condition is $c_{f 11}^{N^{*}}=\frac{1-c_{L}}{2}$, and the retailer's optimal pricing is $p_{11}^{N^{*}}=\frac{c_{L}+3}{4}$.

2.2.2 Single retailer providing products at multiple quality levels 
The basic hypothesis remains unchanged. It is now assumed that a retailer can choose to sell both high-quality product $\mathrm{H}$ and low-quality product $\mathrm{L}$ on the e-commerce platform at the same time. Consumers can only purchase one product based on their own value of goods, assuming $\mu_{Y}$ is the high-quality product rate in the market at this time $\left(\mu_{Y}=q_{H} /\left(q_{H}+q_{L}\right)\right)$. At this time, the market demands $i(i \in\{H, L\})$ of products are respectively

$$
\begin{gathered}
q_{H}=1-p_{H}, \\
q_{L}=p_{H}-p_{L} .
\end{gathered}
$$

The profit functions of online retailers and e-commerce platforms are respectively

$$
\begin{gathered}
\pi^{R}\left(p_{H}, p_{L}\right)=\left(p_{H}-c_{H}\right) q_{H}-c_{f} q_{H}+\left(p_{L}-c_{L}\right) q_{L}-c_{f} q_{L}-c_{F}, \\
\pi^{P}=c_{F}+c_{f} q_{H}+c_{f} q_{L} .
\end{gathered}
$$

Proposition 2. When the platform has no discount and the retailer provides both high- and low-quality products,

(1) The retailer's optimal decisions are $p_{H 21}^{N^{*}}=\frac{7 c_{H}-5 c_{L}+10}{12}, p_{L 21}^{N^{*}=\frac{c_{H}+c_{L}+4}{6}}$, maximum profit is $\pi_{21}^{R N^{*}}=\frac{\left(13 c_{H}{ }^{2}+13 c_{L}^{2}-22 c_{H} c_{L}-4 c_{H}-4 c_{L}+4\right)}{48}-c_{F}$;

(2) The platform's optimal decision is $c_{f 21}^{N^{*}}=\frac{2-c_{H}-c_{L}}{4}$, maximum profit is $\pi_{21}^{P N^{*}}=$ $\frac{\left(2-c_{H}-c_{L}\right)^{2}}{24}+c_{F}$.

Proof: When retailers provide both high- and low-quality products, their profit function is

$$
\pi^{R}\left(p_{H}, p_{L}\right)=\left(p_{H}-c_{H}\right) q_{H}-c_{f} q_{H}+\left(p_{L}-c_{L}\right) q_{L}-c_{f} q_{L}-c_{F}
$$

The first derivatives of $\pi^{R}\left(p_{H}, p_{L}\right)$ for $p_{H}$ and $p_{L}$ are obtained respectively, which is

$$
\begin{gathered}
\frac{\partial \pi^{R}\left(p_{H}, p_{L}\right)}{\partial p_{H}}=1-2 p_{H}+c_{H}+p_{L}-c_{L}=0, \\
\frac{\partial \pi^{R}\left(p_{H}, p_{L}\right)}{\partial p_{L}}=p_{H}-2 p_{L}+c_{L}+c_{f}=0 .
\end{gathered}
$$


And the second derivatives of $\pi^{R}\left(p_{H}, p_{L}\right)$ for $p_{H}$ and $p_{L}$ are obtained respectively

$$
\begin{aligned}
& \frac{\partial^{2} \pi^{R}\left(p_{H}, p_{L}\right)}{\partial p_{H}^{2}}=-2, \frac{\partial^{2} \pi^{R}\left(p_{H}, p_{L}\right)}{\partial p_{H} p_{L}}=1 \\
& \frac{\partial^{2} \pi^{R}\left(p_{H}, p_{L}\right)}{\partial p_{L}^{2}}=-2, \frac{\partial^{2} \pi^{R}\left(p_{H}, p_{L}\right)}{\partial p_{L} p_{H}}=1
\end{aligned}
$$

According to formula (22), the Hessian matrix of $\pi^{R}\left(p_{H}, p_{L}\right)$ is

$$
H\left(p_{H}, p_{L}\right)=\left[\begin{array}{cc}
-2 & 1 \\
1 & -2
\end{array}\right]
$$

According to formula (23), $\left|H_{1}\left(p_{H}, p_{L}\right)\right|=-2<0$, and $\left|H_{2}\left(p_{H}, p_{L}\right)\right|=3>0$. Therefore, Hessian matrix $H\left(p_{H}, p_{L}\right)$ is negative definite. By combining formula (20) with formula (21)

$$
p_{H}^{N^{*}}=\frac{c_{f}+2 c_{H}-c_{L}+2}{3}, p_{L}^{N^{*}}=\frac{2 c_{f}+c_{H}+c_{L}+1}{3}
$$

At this time, the profit of the platform is

$$
\pi^{p}=c_{F}+c_{f} \frac{2-c_{H}-c_{L}-2 c_{f}}{3}
$$

The first derivatives of $\pi^{p}$ for deposit $c_{F}$ and transaction cost $c_{f}$ are obtained respectively

$$
\frac{\partial \pi^{p}}{\partial c_{F}}=1, \frac{\partial \pi^{p}}{\partial c_{f}}=\frac{\left(2-c_{H}-c_{L}-4 c_{f}\right)}{3} .
$$

And the second derivatives of $\pi^{p}$ for deposit $c_{F}$ and transaction cost $c_{f}$ are obtained respectively

$$
\frac{\partial^{2} \pi^{p}}{\partial c_{F}{ }^{2}}=0, \frac{\partial^{2} \pi^{p}}{\partial c_{F} c_{f}}=0, \frac{\partial^{2} \pi^{p}}{\partial c_{f}{ }^{2}}=-\frac{4}{3}, \frac{\partial^{2} \pi^{p}}{\partial c_{f} c_{F}}=0 .
$$

Thus, the Hessian matrix of $\pi^{p}$ is 


$$
H\left(c_{F}, c_{f}\right)=\left[\begin{array}{cc}
0 & 0 \\
0 & -\frac{4}{3}
\end{array}\right]
$$

According to the above solution process, the optimal decision of the platform is not affected by the deposit $c_{F}$, and because the second derivative $\frac{\partial^{2} \pi^{p}}{\partial c_{f}{ }^{2}}$ is less than 0 , if $\frac{\partial \pi^{p}}{\partial c_{f}}=0$, the optimal pricing of the platform is

$$
c_{f 21}^{N^{*}}=\frac{2-c_{H}-c_{L}}{4} .
$$

Substituting it into formula (24), the retailer's optimal pricing is

$$
p_{H 21}^{N^{*}}=\frac{7 c_{H}-5 c_{L}+10}{12}, p_{L 21}^{N^{*}}=\frac{c_{H}+c_{L}+4}{6} .
$$

Maximum profit is

$$
\pi_{21}^{R N^{*}}=\frac{13 c_{H}^{2}+13 c_{L}^{2}-22 c_{H} c_{L}-4 c_{H}-4 c_{L}+4}{48}-c_{F}
$$

At this time, the maximum profit obtained by the platform is

$$
\pi_{21}^{P N^{*}}=\frac{2-c_{H}-c_{L}}{12}\left(2-c_{H}-c_{L}-\frac{2-c_{H}-c_{L}}{2}\right)+c_{F}=\frac{\left(2-c_{H}-c_{L}\right)^{2}}{24}+c_{F}
$$

At this time, the quality product rate in the market is

$$
\mu_{Y 21}=\frac{2-7 c_{H}+5 c_{L}}{4-2 c_{H}-2 c_{L}}
$$

Proven.

\subsection{Optimal Decision Analysis of Platform and Retailer with Platform Discount}

\subsubsection{Single retailer providing single quality products}

When the platform offers discounts, the profit functions of online retailers and e-commerce platforms are 
Article History: Received: 10 May 2021 Revised: 20 June 2021 Accepted: 18 July 2021 Publication: 31 August 2021

$$
\begin{gathered}
\pi_{H}^{R}=\left(p_{H}-c_{H}\right) q_{H}-\alpha c_{F}-\beta c_{f} q_{H}, \\
\pi_{H}^{P}=\alpha c_{F}+\beta c_{f} q_{H} .
\end{gathered}
$$

Lemma 3. When the platform offers discount and the retailer provides only high-quality products,

(1) The retailer's optimal decision is $p_{H 12}^{N^{*}}=\frac{c_{H}+3}{4}$, maximum profit is $\pi_{H 12}^{R N^{*}}=\frac{\left(1-c_{H}\right)^{2}}{16}-\alpha c_{F}$;

(2) The platform's optimal decision is $\beta c_{f 12}^{N^{*}}=\frac{1-c_{H}}{2}$, maximum profit is $\pi_{H 12}^{P N^{*}}=\frac{\left(1-c_{H}\right)^{2}}{8}+\alpha c_{F}$.

Proof: When retailers choose to provide high-quality products $\mathrm{H}$, their profit function is

$$
\pi_{H}^{R}=\left(p_{H}-c_{H}\right) q_{H}-\alpha c_{F}-\beta c_{f} q_{H}
$$

The first derivative and the second derivative of the product price ${ }^{p_{H}}$ are

$$
\frac{d \pi_{H}^{R}}{d p_{H}}=1-2 p_{H}+c_{H}+\beta c_{f}, \frac{d^{2} \pi_{H}^{R}}{d p_{H}^{2}}=-2
$$

Because the second derivative $<0$ shows that $\pi_{H}^{R}$ is a concave function of $p_{H}$, so the optimal pricing for online retailers with $\frac{d \pi_{H}^{R}}{d p_{H}}=0$ is

$$
p_{H}^{N^{*}}=\frac{1+c_{H}+\beta c_{f}}{2} .
$$

At this time, the profit of the platform is

$$
\pi_{H}^{P}=\alpha c_{F}+\frac{\beta c_{f}}{2}\left(1-c_{H}-\beta c_{f}\right)
$$

As the fixed fee $\alpha c_{F}$ determined by deposit discount $\alpha$ and deposit $c_{F}$ is directly determined by the platform, the profit $\pi_{H}^{P}$ of the platform is divided into $\pi_{H}^{P G}$ and $\pi_{H}^{P B}$, then we have

$$
\begin{gathered}
\pi_{H}^{P G}=\alpha c_{F}, \\
\pi_{H}^{P B}=\frac{\beta c_{f}}{2}\left(1-c_{H}-\beta c_{f}\right) .
\end{gathered}
$$


The first derivatives of $\pi_{H}^{P B}$ for transaction cost discount $\beta$ and transaction cost $c_{f}$ are obtained respectively

$$
\frac{\partial \pi_{H}^{P B}}{\partial \beta}=\frac{c_{f}\left(1-c_{H}-2 \beta c_{f}\right)}{2}, \frac{\partial \pi_{H}^{P B}}{\partial c_{f}}=\frac{\beta\left(1-c_{H}-2 \beta c_{f}\right)}{2}
$$

And the second derivatives of $\pi_{H}^{P B}$ for transaction cost discount $\beta$ and transaction cost $c_{f}$ are obtained respectively

$$
\begin{aligned}
& \frac{\partial^{2} \pi_{H}^{P B}}{\partial \beta^{2}}=-c_{f}^{2}, \frac{\partial^{2} \pi_{H}^{P B}}{\partial \beta c_{f}}=\frac{\left(1-c_{H}-4 \beta c_{f}\right)}{2}, \\
& \frac{\partial^{2} \pi_{H}^{P B}}{\partial c_{f} \beta}=\frac{\left(1-c_{H}-4 \beta c_{f}\right)}{2}, \frac{\partial^{2} \pi_{H}^{P B}}{\partial c_{f}{ }^{2}}=-\beta^{2} .
\end{aligned}
$$

Thus, the Hessian matrix of $\pi_{H}^{P B}$ is

$$
H\left(\beta, \quad c_{f}\right)=\left[\begin{array}{cc}
-c_{f}^{2} & \frac{\left(1-c_{H}-4 \beta c_{f}\right)}{2} \\
\frac{\left(1-c_{H}-4 \beta c_{f}\right)}{2} & -\beta^{2}
\end{array}\right] .
$$

According to formula (44), $\left|H_{1}\left(\beta, c_{f}\right)\right|=-c_{f}^{2}<0$, and $\left|H_{2}\left(\beta, c_{f}\right)\right|>0$. Therefore, Hessian matrix $H\left(\beta, c_{f}\right)$ is negative definite. If, $\frac{\partial \pi_{H}^{P B}}{\partial \beta}=0, \frac{\partial \pi_{H}^{P B}}{\partial c_{f}}=0$ in formula (42), by combining both formulas

$$
\beta c_{f 12}^{N^{*}}=\frac{1-c_{H}}{2}
$$

Substituting it into formula (38), the retailer's optimal pricing is

$$
p_{12}^{N^{*}}=\frac{2+2 c_{H}+1-c_{H}}{4}=\frac{c_{H}+3}{4} .
$$

Maximum profit is 


$$
\pi_{H 12}^{R N^{*}}=\left(\frac{c_{H}+3}{4}-c_{H}-\frac{1-c_{H}}{2}\right)\left(1-\frac{c_{H}+3}{4}\right)-\alpha c_{F}=\frac{\left(1-c_{H}\right)^{2}}{16}-\alpha c_{F}
$$

At this time, the maximum profit obtained by the platform is

$$
\pi_{H 12}^{P N^{*}}=\frac{1-c_{H}}{4}\left(1-c_{H}-\frac{1-c_{H}}{2}\right)+\alpha c_{F}=\frac{\left(1-c_{H}\right)^{2}}{8}+\alpha c_{F} .
$$

Proven.

The same applies to the optimal decision when the retailer only offers low-quality products, as shown in Lemma 4.

Lemma 4. When the platform offers discount and the retailer provides only low-quality products,

(1) The retailer's optimal decision is $p_{L 12}^{N^{*}}=\frac{c_{L}+3}{4}$, maximum profit is $\pi_{L 12}^{R N^{*}}=\frac{\left(1-c_{L}\right)^{2}}{16}-c_{F}$;

(2) The platform's optimal decision is $c_{f 12}^{N^{*}}=\frac{1-c_{L}}{2}$, maximum profit is $\pi_{L 12}^{P N^{*}}=\frac{\left(1-c_{L}\right)^{2}}{8}+c_{F}$.

Proof: Same as the proof principle of proposition 4, omitted here.

The comparison of the maximum profit under the retailer's two choices reveals that if both the retailer and the platform aim at profit maximization, the decision will be as shown in Proposition 3.

Proposition 3. (1) Retailer's decision: when $(1-\alpha) c_{F}>\Delta_{1}, \pi_{H}^{R N^{*}}>\pi_{L}^{R N^{*}}$; when $(1-\alpha) c_{F} \leq \Delta_{1}$, $\pi_{H}^{R N^{*}}>\pi_{L}^{R N^{*}}$, where $\Delta_{1}=\frac{\left(2-c_{H}-c_{L}\right)\left(c_{H}-c_{L}\right)}{16}$. (2) Platform's decision: $\pi_{L}^{P N^{*}}>\pi_{H}^{P N^{*}}$.

Proof: The comparison of the maximum profit under the retailer's two choices reveals that

$$
\begin{aligned}
& \pi_{L 12}^{R N^{*}}-\pi_{H 12}^{R N^{*}}=\frac{\left(1-c_{L}\right)^{2}}{16}-c_{F}-\frac{\left(1-c_{H}\right)^{2}}{16}+\alpha c_{F}=\frac{\left(c_{H}-c_{L}\right)\left(2-c_{H}-c_{L}\right)}{16}-(1-\alpha) c_{F} . \\
& \text { If }^{\Delta_{1}=\frac{\left(2-c_{H}-c_{L}\right)\left(c_{H}-c_{L}\right)}{16}} \text {, when }(1-\alpha) c_{F}>\Delta_{1}, \pi_{H}^{R N^{*}}>\pi_{L}^{R N^{*}}, \text { otherwise } \pi_{L}^{R N^{*}} \leq \pi_{H}^{R N^{*}} .
\end{aligned}
$$




$$
\text { As } c_{H}>c_{L}, \text { so }_{L}^{P N^{*}}>\pi_{H}^{P N^{*}} \text {. Proven. }
$$

Proposition 3 shows that when the platform offers discounts and retailers can only choose products of one quality level, the retailer's optimal decision is influenced by the platform deposit strategy and the respective unit costs of high- and low-quality products, and the platform's optimal decision tends to provide low-quality products. Retailers tend to provide high-quality products when the required deposit is high and low-quality products when the required deposit is low to maximize their own interests. Notably, if only measured from the profit dimension, the optimal decision of the platform always tends to provide low-quality products, so the platform cannot spontaneously form an effective autonomy, and the external management regulation is still very important.

\subsubsection{Single retailer providing products at multiple quality levels}

When the platform offers discounts, the profit functions of online retailers and e-commerce platforms are

$$
\begin{array}{r}
\pi^{R}\left(p_{H}, p_{L}\right)=\left(p_{H}-c_{H}\right) q_{H}-\alpha c_{F}-\beta c_{f} q_{H}+\left(p_{L}-c_{L}\right) q_{L}-c_{f} q_{L}, \\
\pi^{P}=\alpha c_{F}+\beta c_{f} q_{H}+c_{f} q_{L} .
\end{array}
$$

Proposition 4. When the platform offers discount and the retailer provides both high- and low-quality products,

(1) The retailer's optimal decisions are $p_{H 22}^{N^{*}}=\frac{2 c_{H}-c_{L}+5}{6}, p_{L 22}^{N^{*}}=\frac{c_{H}+c_{L}+4}{6}$, maximum profit is $\pi_{22}^{R N^{*}}=\frac{\left(c_{H}{ }^{2}+c_{L}{ }^{2}-c_{H} c_{L}-c_{H}-c_{L}+1\right)}{12}-\alpha c_{F}$;

(2) The platform's optimal decisions are $\beta_{22}^{N^{*}}=\frac{1-c_{H}}{1-c_{L}}, c_{f 22}^{N^{*}}=\frac{1-c_{L}}{2}$, maximum profit is $\pi_{22}^{P N^{*}}=\frac{\left(c_{H}{ }^{2}+c_{L}{ }^{2}-c_{H} c_{L}-c_{H}-c_{L}+1\right)}{6}+\alpha c_{F}$.

Proof: The first derivatives of $\pi^{R}\left(p_{H}, p_{L}\right)$ for $p_{H}$ and $p_{L}$ are obtained respectively, which is

$$
\begin{gathered}
\frac{\partial \pi^{R}\left(p_{H}, p_{L}\right)}{\partial p_{H}}=1-2 p_{H}+c_{H}+\beta c_{f}+p_{L}-c_{L}-c_{f}=0, \\
\frac{\partial \pi^{R}\left(p_{H}, p_{L}\right)}{\partial p_{L}}=p_{H}-2 p_{L}+c_{L}+c_{f}=0 .
\end{gathered}
$$


And the second derivatives of $\pi^{R}\left(p_{H}, p_{L}\right)$ for $p_{H}$ and $p_{L}$ are obtained respectively

$$
\begin{aligned}
& \frac{\partial^{2} \pi^{R}\left(p_{H}, p_{L}\right)}{\partial p_{H}{ }^{2}}=-2, \frac{\partial^{2} \pi^{R}\left(p_{H}, p_{L}\right)}{\partial p_{H} p_{L}}=1, \\
& \frac{\partial^{2} \pi^{R}\left(p_{H}, p_{L}\right)}{\partial p_{L}^{2}}=-2, \frac{\partial^{2} \pi^{R}\left(p_{H}, p_{L}\right)}{\partial p_{L} p_{H}}=1 .
\end{aligned}
$$

According to formula (53), the Hessian matrix of $\pi^{R}\left(p_{H}, p_{L}\right)$ is

$$
H\left(p_{H}, p_{L}\right)=\left[\begin{array}{cc}
-2 & 1 \\
1 & -2
\end{array}\right]
$$

According to formula (54), $\left|H_{1}\left(p_{H}, p_{L}\right)\right|=-2<0$, and $\left|H_{2}\left(p_{H}, p_{L}\right)\right|=3>0$. Therefore, Hessian matrix $H\left(p_{H}, p_{L}\right)$ is negative definite. By combining formula (49) with formula (50)

$$
p_{H}^{N^{*}}=\frac{2+2 c_{H}-c_{L}+(2 \beta-1) c_{f}}{3}, p_{L}^{N^{*}}=\frac{1+c_{H}+c_{L}+(\beta+1) c_{f}}{3} .
$$

At this time, the profit of the platform is

$$
\pi^{P}=\alpha c_{F}+\frac{\left(1-2 c_{H}+c_{L}\right) \beta c_{f}+\left(1+c_{H}-2 c_{L}\right) c_{f}-2\left(\beta^{2}-\beta+1\right) c_{f}^{2}}{3}
$$

As the fixed fee $\alpha c_{F}$ determined by deposit discount $\alpha$ and deposit $c_{F}$ is directly determined by the platform, the profit $\pi^{P}$ of the platform is divided into $\pi^{P G}$ and $\pi^{P B}$

$$
\begin{gathered}
\pi^{P G}=\alpha c_{F}, \\
\pi^{P B}=\frac{\left(1-2 c_{H}+c_{L}\right) \beta c_{f}+\left(1+c_{H}-2 c_{L}\right) c_{f}-2\left(\beta^{2}-\beta+1\right) c_{f}^{2}}{3} .
\end{gathered}
$$

The first derivatives of $\pi^{P B}$ for transaction cost discount $\beta$ and transaction cost ${ }^{c_{f}}$ are obtained respectively

$$
\frac{\partial \pi^{P B}}{\partial \beta}=\frac{\left(1-2 c_{H}+c_{L}\right) c_{f}-2(2 \beta-1) c_{f}^{2}}{3},
$$




$$
\frac{\partial \pi^{P B}}{\partial c_{f}}=\frac{\left(1-2 c_{H}+c_{L}\right) \beta-4\left(\beta^{2}-\beta+1\right) c_{f}+\left(1+c_{H}-2 c_{L}\right)}{3}
$$

And the second derivatives of $\pi^{P B}$ for transaction cost discount $\beta$ and transaction cost ${ }_{f}$ are obtained respectively:

$$
\begin{gathered}
\frac{\partial^{2} \pi^{P B}}{\partial \beta^{2}}=-\frac{4}{3} c_{f}^{2}, \frac{\partial^{2} \pi^{P B}}{\partial \beta c_{f}}=\frac{\left(1-2 c_{H}+c_{L}\right)-4(2 \beta-1) c_{f}}{3} \\
\frac{\partial^{2} \pi^{P B}}{\partial c_{f} \beta}=\frac{\left(1-2 c_{H}+c_{L}\right)-4(2 \beta-1) c_{f}}{3}, \frac{\partial^{2} \pi^{P B}}{\partial c_{f}^{2}}=-\frac{4}{3}\left(\beta^{2}-\beta+1\right) .
\end{gathered}
$$

Thus, the Hessian matrix of $\pi^{P B}$ is

$$
H\left(\beta, c_{f}\right)=\left[\begin{array}{cc}
-\frac{4}{3} c_{f}^{2} & \frac{\left(1-2 c_{H}+c_{L}\right)-4(2 \beta-1) c_{f}}{3} \\
\frac{\left(1-2 c_{H}+c_{L}\right)-4(2 \beta-1) c_{f}}{3} & -\frac{4}{3}\left(\beta^{2}-\beta+1\right)
\end{array}\right] .
$$

According to formula (61), $\left|H_{1}\left(\beta, c_{f}\right)\right|=-\frac{4}{3} c_{f}^{2}<0$, and $\left|H_{2}\left(\beta, c_{f}\right)\right|>0$. Therefore, Hessian matrix $H\left(\beta, c_{f}\right)$ is negative definite. If, $\frac{\partial \pi^{P B}}{\partial \beta}=0, \frac{\partial \pi^{P B}}{\partial c_{f}}=0$ in formula (59), by combining both formulas, the optimal pricing of the platform is

$$
\beta_{22}^{N^{*}}=\frac{1-c_{H}}{1-c_{L}}, c_{f 22}^{N^{*}}=\frac{1-c_{L}}{2}
$$

Substituting it into formula (55), the retailer's optimal pricing is

$$
\begin{gathered}
p_{H 22}^{N^{*}}=\frac{4+4 c_{H}-2 c_{L}+1-2 c_{H}+c_{L}}{6}=\frac{2 c_{H}-c_{L}+5}{6}, \\
p_{L 22}^{N^{*}}=\frac{2-c_{H}-c_{L}+2+2 c_{H}+2 c_{L}}{6}=\frac{c_{H}+c_{L}+4}{6} .
\end{gathered}
$$

Maximum profit is 


$$
\pi_{22}^{R N^{*}}=\left(\frac{2-c_{H}-c_{L}}{6}\right)\left(\frac{1-2 c_{H}+c_{L}}{6}\right)+\left(\frac{c_{H}-2 c_{L}+1}{6}\right)^{2}-\alpha c_{F}=\frac{\left(c_{H}{ }^{2}+c_{L}{ }^{2}-c_{H} c_{L}-c_{H}-c_{L}+1\right)}{12}-\alpha c_{F} .
$$

At this time, the maximum profit obtained by the platform is

$$
\pi_{22}^{P N^{*}}=\frac{1-c_{H}}{2}\left(1-\frac{2 c_{H}-c_{L}+5}{6}\right)+\frac{1-c_{L}}{2} \frac{c_{H}-2 c_{L}+1}{6}+\alpha c_{F}=\frac{\left(c_{H}{ }^{2}+c_{L}{ }^{2}-c_{H} c_{L}-c_{H}-c_{L}+1\right)}{6}+\alpha c_{F} .
$$

At this time, the quality product rate in the market is

$$
\mu_{Y 22}=\frac{1-2 c_{H}+c_{L}}{2-c_{H}-c_{L}}
$$

Proven.

\subsection{Comparative Analysis on Incentive Effect of Discount}

According to the above analysis results, the incentive effect in the case of a single retailer is as described in Corollary 1 and Corollary 2.

Corollary 1 . When a single retailer chooses to sell a product of a quality level, the platform discount can effectively encourage retailers to provide high-quality products to a certain extent, and the effectiveness of the incentive mechanism depends on the deposit strategy of the platform and the influence of the respective unit costs of high- and low-quality products.

Proof: It can be easily obtained by comparing the relevant conclusions of Proposition 1 and Proposition 3, omitted here.

When no discount is offered, the retailer can only choose the product of one quality level, and the retailer's optimal decision tends to provide low-quality products to maximize the benefits.

When the platform offers discounts, the retailer's choice of quality products to offer depends on the platform's deposit strategy and the influence of the unit costs of high- and lowquality products. When the transaction cost $(1-\alpha) c_{F}$ reduced by the platform through deposit discount is higher than a certain threshold, the platform discount has a positive incentive effect on online retailers, and the platform subsidizes the cost incurred by retailers in providing highquality products by reducing the transaction cost. With the increasing of $(1-\alpha) c_{F}$ value, the 
retailer's profit from providing high-quality products will gradually increase, and the retailer is more willing to provide high-quality products. When the transaction cost $(1-\alpha) c_{F}$ reduced by the deposit discount on the platform is lower than a certain threshold, the platform discount cannot subsidize the cost incurred by retailers in providing high-quality products, and rational retailers will inevitably choose to provide low-cost and low-quality products on the platform, thus causing the low-quality products on the platform to drive out the high-quality products. At this time, the incentive mechanism of the platform is ineffective.

Corollary 2. When a single retailer sells high- and low-quality products at the same time, the incentive mechanism of platform discount is completely effective, and the price discount of platform has a positive incentive effect on retailers, which improves the rate of high-quality products in the market.

Proof: Since $\mu_{Y 21}-\mu_{Y 22}=\frac{2-7 c_{H}+5 c_{L}}{4-2 c_{H}-2 c_{L}}-\frac{1-2 c_{H}+c_{L}}{2-c_{H}-c_{L}}=\frac{3\left(c_{L}-c_{H}\right)}{2\left(2-c_{H}-c_{L}\right)}$ and $c_{H}>c_{L}$, so $\mu_{Y 22}>\mu_{Y 21}$. Proven.

When a single retailer sells both high- and low-quality products at the same time, the incentive mechanism of platform discount is completely effective, and the price discount of platform has a positive incentive effect on retailers. Influenced by unit transaction $\operatorname{cost} c$ and price discount coefficient $\beta$, retailers increase the sales of high-quality products, reduce the sales of low-quality products, which will improve the rate of high-quality products in the market. When ${ }^{c_{L}}$ is fixed, with the increase of unit cost of high-quality products ${ }^{c_{H}}$, the market rate of high-quality products when the platform offers discount is higher than that without discount. At this time, the platform discount has a more obvious incentive effect on retailers' product quality improvement.

\section{QUALITY INCENTIVE OF E-COMMERCE PLATFORM IN CASE OF MULTIPLE RETAILERS}

\subsection{Model and Hypothesis}

With the basic hypothesis unchanged, the supply chain consisting of two online retailers (high-quality retailer $\mathrm{H}$ and low-quality retailer $\mathrm{L}$ ) and an e-commerce platform is considered. High-quality retailers provide high-quality products, and determine the sales price of the products $p_{H}$, with the unit cost of the corresponding products of ${ }^{c_{H}}$, while low-quality retailers provide low-quality products, and determine the sales price of the products ${ }^{p_{L}}$, with the unit 
cost of the corresponding products of ${ }^{c_{L}}$, without loss of generality, $c_{H}>c_{L}$. Assuming that $\mu_{Y}$ is the high-quality product rate in the market $\left(\mu_{Y}=q_{H} /\left(q_{H}+q_{L}\right)\right)$.

\subsubsection{Optimal decision analysis of platform and retailer without platform discount}

When the platform does not offer discounts, the market demands of product $i\left({ }^{i \in\{H, L\}}\right)$ are

$$
\begin{gathered}
q_{H}=1-p_{H}, \\
q_{L}=p_{H}-p_{L} .
\end{gathered}
$$

The profit functions of online retailers and e-commerce platforms are

$$
\begin{gathered}
\pi_{i}^{R}=\left(p_{i}-c_{i}\right) q_{i}-c_{F}-c_{f} q_{i}, \\
\pi^{P}=2 c_{F}+c_{f} q_{H}+c_{f} q_{L} .
\end{gathered}
$$

Proposition 5. When the platform does not offer discounts, one retailer sells high-quality products and one retailer sells low-quality products:

(1) The optimal decisions of two retailers are $p_{H 31}^{N^{*}}=\frac{9+5 c_{H}-2 c_{L}}{12}, p_{L 31}^{N^{*}=\frac{5+c_{H}+2 c_{L}}{8}}$, and the maximum profits are respectively

$$
\pi_{H 31}^{R N *}=\left(\frac{3-5 c_{H}+2 c_{L}}{12}\right)^{2}-c_{F} \quad \pi_{L 31}^{R N^{*}}=\left(\frac{3+7 c_{H}-10 c_{L}}{24}\right)^{2}-c_{F}
$$

(2) The platform's optimal decision is $c_{f 31}^{N^{*}}=\frac{3-c_{H}-2 c_{L}}{6}$, and maximum profit is $\frac{\left(3-c_{H}-2 c_{L}\right)^{2}}{48}$.

Proof: When one retailer chooses to provide high-quality products $\mathrm{H}$, while the other lowquality products $\mathrm{L}$, their profit functions are respectively

$$
\begin{gathered}
\pi_{H}^{R}=\left(p_{H}-c_{H}\right) q_{H}-c_{F}-c_{f} q_{H}, \\
\pi_{L}^{R}=\left(p_{L}-c_{L}\right) q_{L}-c_{F}-c_{f} q_{L} .
\end{gathered}
$$

The first derivative and the second derivative of the product price $p_{H}$ of $\pi_{H}^{R}$ are

$$
\frac{d \pi_{H}^{R}}{d p_{H}}=1-2 p_{H}+c_{H}+c_{f}, \frac{d^{2} \pi_{H}^{R}}{d p_{H}{ }^{2}}=-2 .
$$


Because the second derivative $<0$ shows that $\pi_{H}^{R}$ is a concave function of $p_{H}$, so the optimal pricing for quality retailers with $\frac{d \pi_{H}^{R}}{d p_{H}}=0$ is

$$
p_{H}^{N^{*}}=\frac{1+c_{H}+c_{f}}{2}
$$

At this time, the profit of the platform is

$$
p_{L}^{N *}=\frac{1+c_{H}+2 c_{L}+3 c_{f}}{4}
$$

At this time, the profit of the platform is

$$
\pi^{p}=2 c_{F}+c_{f} \frac{3-c_{H}-2 c_{L}-3 c_{f}}{4} .
$$

The first derivatives of $\pi^{p}$ for deposit $c_{F}$ and transaction cost $c_{f}$ are obtained respectively

$$
\frac{\partial \pi^{p}}{\partial c_{F}}=2, \frac{\partial \pi^{p}}{\partial c_{f}}=\frac{\left(3-c_{H}-2 c_{L}-6 c_{f}\right)}{4}
$$

And the second derivatives of $\pi^{p}$ for deposit $c_{F}$ and transaction cost $c_{f}$ are obtained respectively

$$
\frac{\partial^{2} \pi^{p}}{\partial c_{F}{ }^{2}}=0, \frac{\partial^{2} \pi^{p}}{\partial c_{F} c_{f}}=0, \frac{\partial^{2} \pi^{p}}{\partial c_{f}{ }^{2}}=-\frac{3}{2}, \frac{\partial^{2} \pi^{p}}{\partial c_{f} c_{F}}=0
$$

Thus, the Hessian matrix of $\pi^{p}$ is

$$
H\left(c_{F}, c_{f}\right)=\left[\begin{array}{cc}
0 & 0 \\
0 & -\frac{3}{2}
\end{array}\right]
$$

According to the above solution process, the optimal decision of the platform is not affected by the deposit $c_{F}$, and because the second derivative $\frac{\partial^{2} \pi^{p}}{\partial c_{f}^{2}}$ is less than 0 , if $\frac{\partial \pi^{p}}{\partial c_{f}}=0$, the optimal pricing of the platform is 


$$
c_{f 31}^{N^{*}}=\frac{3-c_{H}-2 c_{L}}{6}
$$

Substituting it into formulas (75) and (76), the retailers' optimal pricings are

$$
\begin{gathered}
p_{H 31}^{N^{*}}=\frac{6+6 c_{H}+3-c_{H}-2 c_{L}}{12}=\frac{9+5 c_{H}-2 c_{L}}{12}, \\
p_{L 31}^{N^{*}}=\frac{9+5 c_{H}-2 c_{L}+12 c_{L}+6-2 c_{H}-4 c_{L}}{24}=\frac{5+c_{H}+2 c_{L}}{8} .
\end{gathered}
$$

Maximum profits are

$$
\begin{gathered}
\pi_{H 31}^{R N^{*}}=\frac{3-5 c_{H}+2 c_{L}}{12}\left(\frac{3-5 c_{H}+2 c_{L}}{12}\right)-c_{F}=\left(\frac{3-5 c_{H}+2 c_{L}}{12}\right)^{2}-c_{F}, \\
\pi_{L 31}^{R N^{*}}=\frac{3+7 c_{H}-10 c_{L}}{24}\left(\frac{3+7 c_{H}-10 c_{L}}{24}\right)-c_{F}=\left(\frac{3+7 c_{H}-10 c_{L}}{24}\right)^{2}-c_{F} .
\end{gathered}
$$

At this time, the maximum profit obtained by the platform is

$$
\pi_{31}^{P N^{*}}=\frac{3-c_{H}-2 c_{L}}{6}\left(\frac{3-c_{H}-2 c_{L}}{8}\right)+2 c_{F}=\frac{\left(3-c_{H}-2 c_{L}\right)^{2}}{48}+2 c_{F}
$$

At this time, the quality product rate in the market is

$$
\mu_{Y 31}=\frac{2\left(3-5 c_{H}+2 c_{L}\right)}{3\left(3-c_{H}-2 c_{L}\right)}=\frac{6-10 c_{H}+4 c_{L}}{9-3 c_{H}-6 c_{L}} .
$$

Proven.

3.1.2 Optimal decision analysis of the platform and retailers with platform discount

When the platform offers discounts, the profit functions of two online retailers and ecommerce platforms are

$$
\begin{gathered}
\pi_{H}^{R}=\left(p_{H}-c_{H}\right) q_{H}-\alpha c_{F}-\beta c_{f} q_{H}, \\
\pi_{L}^{R}=\left(p_{L}-c_{L}\right) q_{L}-c_{F}-c_{f} q_{L}, \\
\pi^{P}=(\alpha+1) c_{F}+\beta c_{f} q_{H}+c_{f} q_{L}
\end{gathered}
$$

Proposition 6. When the platform offers discounts, one retailer sells high-quality products, 
while the other sells low-quality products:

(1) The optimal decisions of two retailers are $p_{H 32}^{N^{*}=\frac{4 c_{H}-c_{L}+12}{15}}, p_{L 32}^{N^{*}=\frac{c_{H}+c_{L}+3}{5}}$, and the maximum profits are respectively

$$
\pi_{H 32}^{R N^{*}}=\left(\frac{3-4 c_{H}+c_{L}}{15}\right)^{2}-\alpha c_{F} \quad \pi_{L 32}^{R N^{*}}=\left(\frac{c_{H}-4 c_{L}+3}{15}\right)^{2}-c_{F}
$$

(2) The platform's optimal decisions are

$$
\beta_{32}^{N^{*}}=\frac{9-7 c_{H}-2 c_{L}}{2 c_{H}-8 c_{L}+6}, \quad c_{f 32}^{N^{*}}=\frac{2 c_{H}-8 c_{L}+6}{15} \text {, and maximum }
$$

profit is

$$
\pi_{32}^{P N^{*}}=(\alpha+1) c_{F}+\frac{\left(2 c_{H}{ }^{2}+2 c_{L}{ }^{2}-c_{H} c_{L}-3 c_{H}-3 c_{L}+3\right)}{15} \text {. }
$$

Proof: The first and second derivatives of $\pi_{H}^{R}$ for product price $p_{H}$ are obtained respectively

$$
\frac{d \pi_{H}^{R}}{d p_{H}}=1-2 p_{H}+c_{H}+\beta c_{f}, \frac{d^{2} \pi_{H}^{R}}{d p_{H}^{2}}=-2
$$

Because the second derivative $<0$ shows that $\pi_{H}^{R}$ is a concave function of $p_{H}$, so the optimal pricing for quality retailers with $\frac{d \pi_{H}^{R}}{d p_{H}}=0$ is

$$
p_{H}^{N^{*}}=\frac{1+c_{H}+\beta c_{f}}{2}
$$

Similarly, the optimal pricing of low-quality retailers is

$$
p_{L}^{N *}=\frac{1+c_{H}+2 c_{L}+\beta c_{f}+2 c_{f}}{4} .
$$

At this time, the profit of the platform is

$$
\pi^{P}=(\alpha+1) c_{F}+\beta c_{f} \frac{1-c_{H}-\beta c_{f}}{2}+c_{f} \frac{1+c_{H}-2 c_{L}+(\beta-2) c_{f}}{4}
$$

As the fixed fee $\alpha c_{F}$ determined by deposit discount $\alpha$ and deposit $c_{F}$ is directly determined by the platform, the profit $\pi^{P}$ of the platform is divided into $\pi^{P G}$ and $\pi^{P B}$, which are

$$
\pi^{P G}=(\alpha+1) c_{F},
$$




$$
\pi^{P B}=\beta c_{f} \frac{1-c_{H}-\beta c_{f}}{2}+c_{f} \frac{1+c_{H}-2 c_{L}+(\beta-2) c_{f}}{4}
$$

The first derivatives of $\pi^{P B}$ for unit transaction cost discount $\beta$ and transaction cost ${ }^{c_{f}}$ are obtained respectively as the following

$$
\begin{gathered}
\frac{\partial \pi^{P B}}{\partial \beta}=\frac{2\left(1-c_{H}\right) c_{f}+(1-4 \beta) c_{f}^{2}}{4}, \\
\frac{\partial \pi^{P B}}{\partial c_{f}}=\frac{1+c_{H}-2 c_{L}+2\left(1-c_{H}\right) \beta+2\left(\beta-2-2 \beta^{2}\right) c_{f}}{4} .
\end{gathered}
$$

And the second derivatives of $\pi^{P B}$ for unit transaction cost discount $\beta$ and transaction cost $c_{f}$ are obtained respectively

$$
\begin{gathered}
\frac{\partial^{2} \pi^{P B}}{\partial \beta^{2}}=-c_{f}^{2}, \frac{\partial^{2} \pi^{P B}}{\partial \beta c_{f}}=\frac{\left(1-c_{H}\right)+(1-4 \beta) c_{f}}{2} \\
\frac{\partial^{2} \pi^{P B}}{\partial c_{f} \beta}=\frac{\left(1-c_{H}\right)+(1-4 \beta) c_{f}}{2}, \frac{\partial^{2} \pi^{P B}}{\partial c_{f}{ }^{2}}=\frac{\left(\beta-2-2 \beta^{2}\right)}{2} .
\end{gathered}
$$

Thus, the Hessian matrix of $\pi^{P B}$ is

$$
H\left(\beta, \quad c_{f}\right)=\left[\begin{array}{cc}
-c_{f}^{2} & \frac{\left(1-c_{H}\right)+(1-4 \beta) c_{f}}{2} \\
\frac{\left(1-c_{H}\right)+(1-4 \beta) c_{f}}{2} & \frac{\left(\beta-2-2 \beta^{2}\right)}{2}
\end{array}\right] .
$$

According to formula (100), $\left|H_{1}\left(\beta, c_{f}\right)\right|=-c_{f}{ }^{2}<0$, and $\left|H_{2}\left(\beta, c_{f}\right)\right|>0$. Therefore, Hessian matrix $H\left(\beta, c_{f}\right)$ is negative definite. If, $\frac{\partial \pi^{P B}}{\partial \beta}=0, \frac{\partial \pi^{P B}}{\partial c_{f}}=0$ in formulas (97) and (98), by combining both formulas, the optimal pricing of the platform is

$$
\beta_{32}^{N^{*}}=\frac{9-7 c_{H}-2 c_{L}}{2 c_{H}-8 c_{L}+6}, c_{f 32}^{N^{*}}=\frac{2 c_{H}-8 c_{L}+6}{15} .
$$

Substituting them into formulas (92) and (93), the optimal pricings of two retailers are 


$$
\begin{gathered}
p_{H 32}^{N *}=\frac{15+15 c_{H}+9-7 c_{H}-2 c_{L}}{30}=\frac{4 c_{H}-c_{L}+12}{15}, \\
p_{L 32}^{N^{*}}=\frac{15+15 c_{H}+30 c_{L}+9-7 c_{H}-2 c_{L}+4 c_{H}-16 c_{L}+12}{60}=\frac{c_{H}+c_{L}+3}{5} .
\end{gathered}
$$

The maximum profits are respectively

$$
\begin{aligned}
& \pi_{H 32}^{R N^{*}}=\frac{11 c_{H}+c_{L}+3-15 c_{H}}{15} \times \frac{3-4 c_{H}+c_{L}}{15}-\alpha c_{F}=\left(\frac{3-4 c_{H}+c_{L}}{15}\right)^{2}-\alpha c_{F}, \\
& \pi_{L 32}^{R N^{*}}=\frac{c_{H}+11 c_{L}+9-15 c_{L}-6}{15} \times \frac{c_{H}-4 c_{L}+3}{15}-c_{F}=\left(\frac{c_{H}-4 c_{L}+3}{15}\right)^{2}-c_{F} .
\end{aligned}
$$

At this time, the optimal profit obtained by the platform is

$$
\pi_{32}^{P N^{*}}=(\alpha+1) c_{F}+\frac{\left(2 c_{H}^{2}+2 c_{L}^{2}-c_{H} c_{L}-3 c_{H}-3 c_{L}+3\right)}{15} .
$$

At this time, the quality product rate in the market is

$$
\mu_{Y 32}=\frac{3-4 c_{H}+c_{L}}{15} \times \frac{5}{2-c_{H}-c_{L}}=\frac{3-4 c_{H}+c_{L}}{3\left(2-c_{H}-c_{L}\right)} .
$$

Proven.

\subsection{Comparative Analysis of Discount Incentive Effect}

According to the above analysis, the incentive effect in this case can be obtained, as described in Corollary 3.

Corollary 3. When there are two retailers, one selling high-quality products and the other selling low-quality products, the platform discount incentive mechanism cannot be fully effective. The effectiveness of the platform discount incentive mechanism is affected by the unit cost of high- and low-quality products.

Proof: $\mu_{Y 32}-\mu_{Y 31}=\frac{3-4 c_{H}+c_{L}}{3\left(2-c_{H}-c_{L}\right)}-\frac{6-10 c_{H}+4 c_{L}}{9-3 c_{H}-6 c_{L}}$

$$
\begin{aligned}
& =\frac{\left(3-4 c_{H}+c_{L}\right)\left(3-c_{H}-2 c_{L}\right)-\left(6-10 c_{H}+4 c_{L}\right)\left(2-c_{H}-c_{L}\right)}{3\left(2-c_{H}-c_{L}\right)\left(3-c_{H}-2 c_{L}\right)} \\
& =\frac{-6 c_{H}{ }^{2}+2 c_{L}{ }^{2}+c_{H} c_{L}+11 c_{H}-5 c_{L}-3}{3\left(2-c_{H}-c_{L}\right)\left(3-c_{H}-2 c_{L}\right)} .
\end{aligned}
$$




$$
\mathrm{As}^{<c_{L}<c_{H}<\text {, so }}\left(2-c_{H}-c_{L}\right)\left(3-c_{H}-2 c_{L}\right) \text {. If } \Delta_{2}=6 c_{H}{ }^{2}-2 c_{L}{ }^{2}-c_{H} c_{L}-11 c_{H}+5 c_{L}+3, \Delta_{2}<0 \text {, then } \mu_{Y 32}
$$
$>\mu_{Y 31}$; if $\Delta_{2} \geq 0$, then $\mu_{Y 32} \leq \mu_{Y 31}$. Proven.

When ${ }^{\Delta_{2}}<0$, under the incentive of platform discount, high-quality retailers have internal incentives to increase high-quality products, which will increase sales of high-quality products, while low-quality retailers have internal incentives to reduce sales of low-quality products, thus $\mu_{Y 32}>\mu_{Y_{31}}$, which will improve the rate of high-quality products in the market. When $\Delta_{2} \geq 0$, even if the platform offers discounts and retailers adopt the optimal pricing, the high-quality product rate cannot be improved, and the platform discounts cannot play an incentive role in upgrading retailers' products, so the incentive mechanism is ineffective. Therefore, when two retailers only sell high-quality products and low-quality products respectively, whether the incentive mechanism of platform discount is effective or not mainly depends on the relationship between the unit costs of the two quality products.

\section{NUMERICAL ANALYSIS}

\subsection{Selection of Optimal Decision and Comparison of Results}

Under the condition that a single retailer provides a single-quality product, the impact of changes in relevant parameters on the retailer's optimal decision-making is further investigated to examine the effectiveness of the platform discount incentive mechanism.
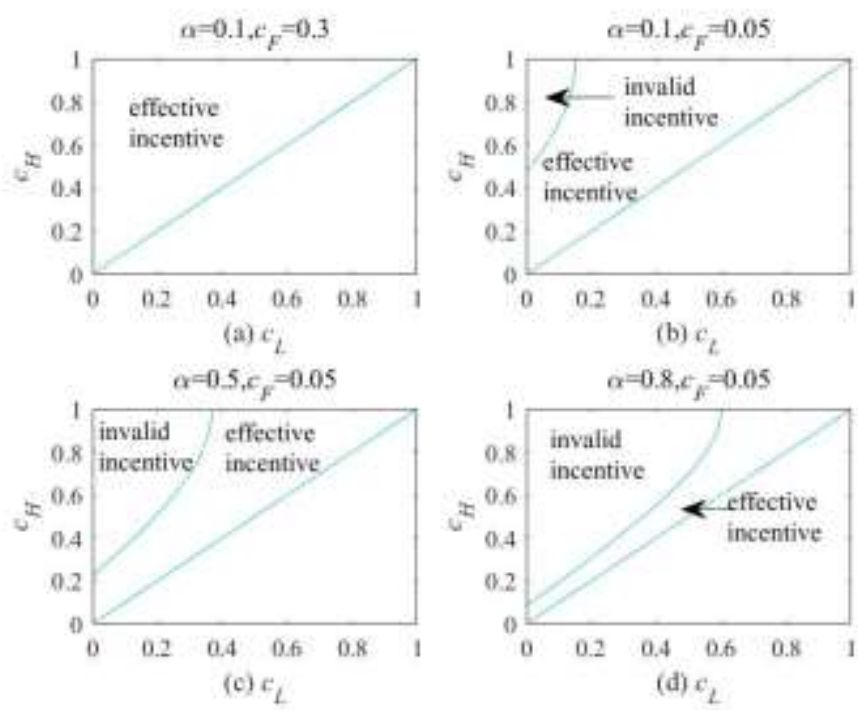
Fig 1: The impact of two product unit costs $c_{H}$ and $c_{L}$ on the platform discount incentive mechanism when $\alpha$ and $c_{F}$ are fixed

Figure 1 shows the impact of unit $\operatorname{cost}^{c_{H}}$ and ${ }^{c_{L}}$ of high- and low-quality products on the retailer's optimal decision and incentive mechanism when the values of $\alpha,{ }_{F}$ are fixed.

Whether the discount incentive mechanism is fully effective is affected by the deposit strategy, that is, the deposit discount $\alpha$ and the deposit $c_{F}$. When ${ }^{(1-\alpha) c_{F}}$ is larger, the space for the incentive mechanism to take effect will become larger, but the incentive mechanism is still partially effective (as shown in b, c and d in Figure 1); when the deposit strategy $(1-\alpha) c_{F}$ reaches a certain threshold, there is $\pi_{H 12}^{R N^{*}}>\pi_{L 12}^{R N^{*}}$ regardless of the values of $c_{H}$ and $c_{L}$, and retailers tend to choose high-quality products when the platform offers discounts, and the incentive mechanism is fully effective then (as shown in a in Figure 1).

When the incentive mechanism is not fully effective, with the increase of ${ }^{c_{L}}$, the threshold of ${ }^{c_{H}}$ which makes the discount incentive mechanism effective will increase, and the space for the incentive mechanism to take effect will gradually increase. When ${ }^{c_{H}}$ is less than the threshold value corresponding to each $c_{L}$ value, $\pi_{H 12}^{R N^{*}}>\pi_{L 12}^{R N^{*}}$, retailers tend to provide highquality products, and then the discount incentive mechanism takes effect. On the contrary, when $c_{H}$ is greater than the threshold value corresponding to each $c_{L}$ value, then $\pi_{L 12}^{R N^{*}}>\pi_{H 12}^{R N^{*}}$, retailers still tend to provide low-quality products, and then the discount incentive mechanism fails. 

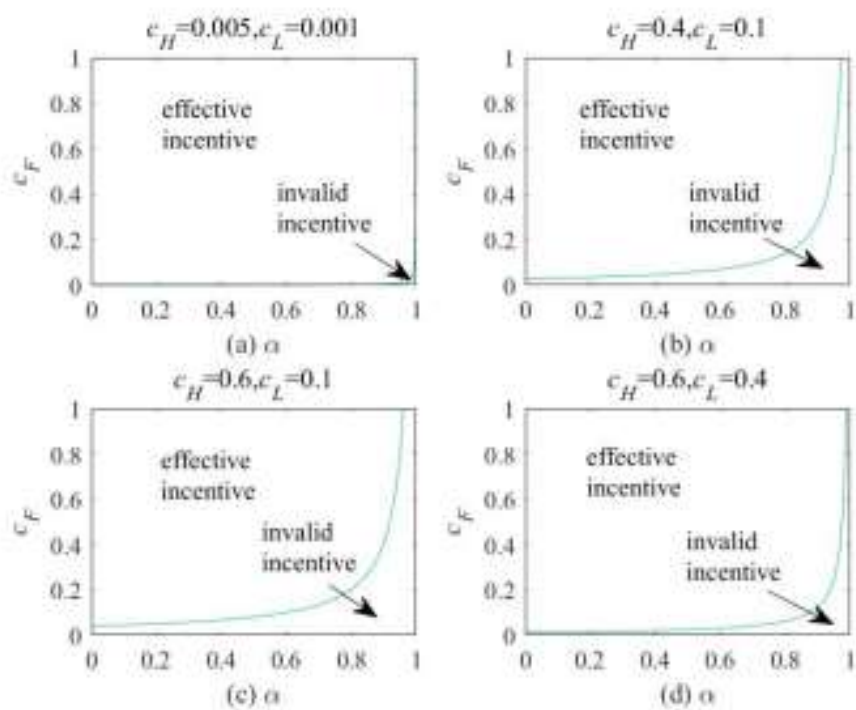

Fig 2: The impact of deposit discount $\alpha$ and deposit $c_{F}$ on the retailer's optimal decision when $c_{H}$ and $c_{L}$ are fixed

Figure 2 shows the impact of deposit discount $\alpha$ and deposit $c_{F}$ on the retailer's optimal decision and incentive mechanism when ${ }^{c_{H}}$ and ${ }^{c_{L}}$ are fixed.

When the values of $c_{H}$ and $c_{L}$ are fixed, with the increase of $\alpha$, the threshold value of $c_{F}$ that makes the discount incentive mechanism take effect will increase. When ${ }^{c_{F}}$ is greater than the threshold value corresponding to each $\alpha$ value, $\pi_{H 12}^{R N^{*}}>\pi_{L 12}^{R N^{*}}$, retailers tend to choose highquality products when the platform offers discounts, and then the incentive mechanism takes effect. On the contrary, when $c_{F}$ is less than the threshold value corresponding to each $\alpha$ value, $\pi_{L 12}^{R N^{*}}>\pi_{H 12}^{R N^{*}}$, retailers still tend to choose low-quality products when the platform offers discounts, and then the incentive mechanism fails.

The smaller the difference $\left(c_{H}-c_{L}\right)$ between high- and low-quality unit costs, the larger the sum $\left(c_{H}+c_{L}\right)$ of unit costs, and the larger the space for the incentive mechanism to take effect (as shown in $\mathrm{c}$ and $\mathrm{d}$ in Figure2,), thus improving the effectiveness of the incentive mechanism.

\subsection{Sensitivity Analysis}

The sensitivity analysis of parameters is conducted to further test the changes of the effect 
of the incentive mechanism in different parameter environments. (1 refers to the situation without discount, 2 refers to the situation where the platform provides discount.)

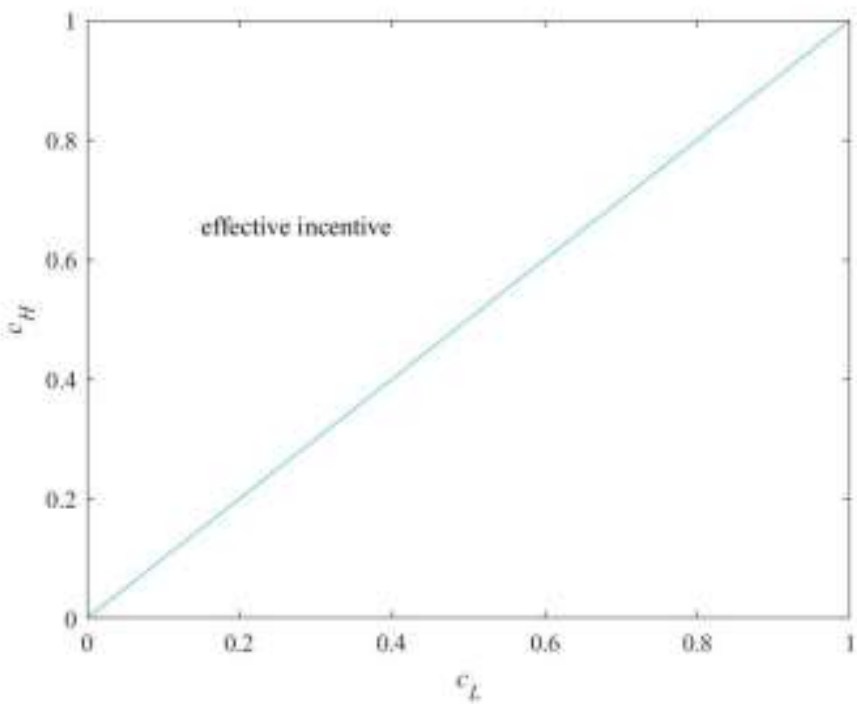

Fig 3: The impact of parameters $c_{H}$ and $c_{L}$ on discount incentive mechanism in the case of single retailer and multiple quality levels
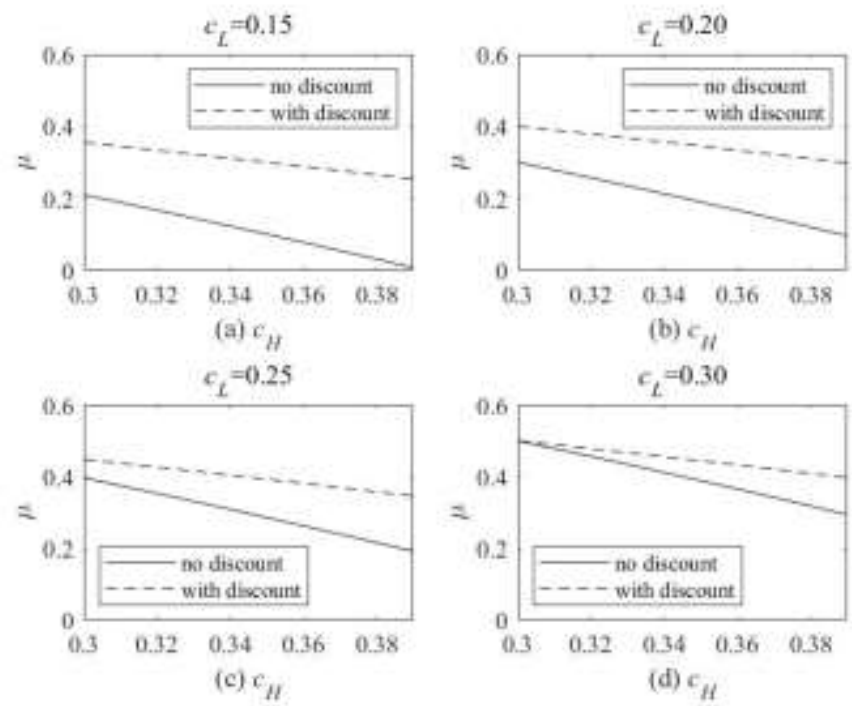

Fig 4: Sensitivity analysis of parameters $c_{H}$ and $c_{L}$ with respect to $\mu$ in case of a single retailer and multiple quality levels

In case of a single retailer providing products at multiple quality levels, Figure 3 and Figure 
4 show that the rate of high-quality products when the platform offers discounts is always higher than that without discounts, and the incentive mechanism of the platform for retailers to improve product quality is fully effective.

And given the value of unit cost ${ }^{c_{L}}$ of low-quality products, whether the platform has discounts or not, the rate of high-quality products in the market will decrease with the increase of ${ }^{c_{H}}$, and the incentive effect will become more obvious with the increase of ${ }^{c_{H}}$.

Also, when given the value of unit cost ${ }^{c_{H}}$ of high-quality products, whether the platform offers discounts or not, with the increase of ${ }^{c_{L}}$, that is, the smaller the difference between unit cost of high- and low-quality products provided by retailers, the higher the rate of high-quality products in the market.

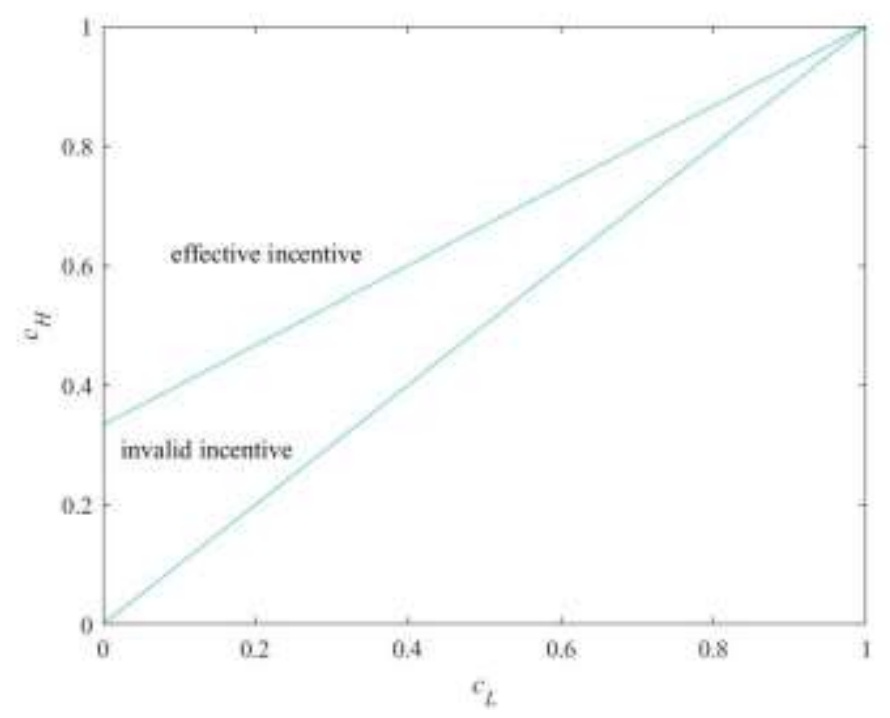

Fig 5: The impact of parameters $c_{H}$ and $c_{L}$ on discount incentive mechanism in the case of multiple retailers 

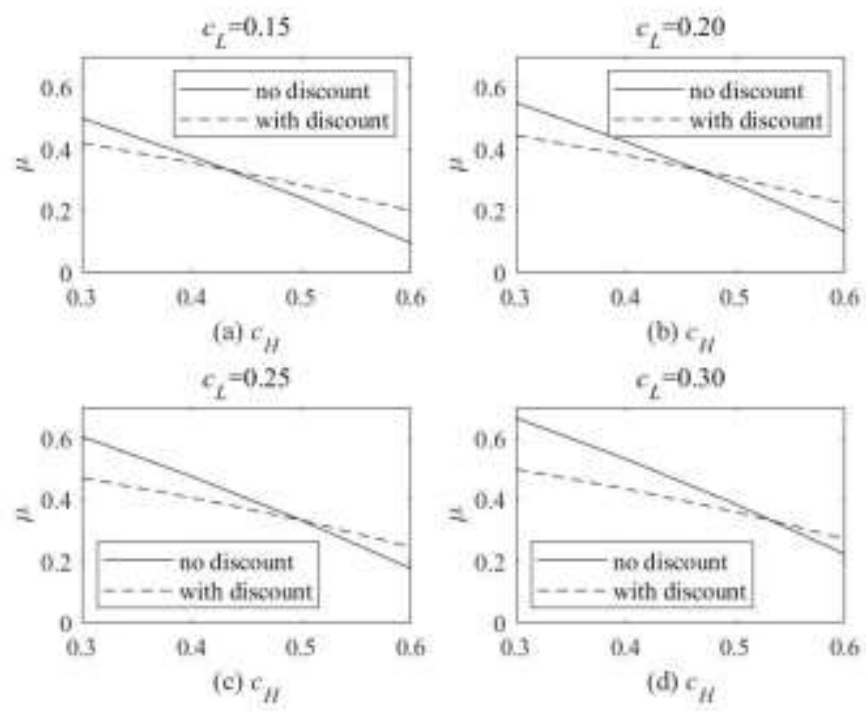

Fig 6: Sensitivity analysis of parameters $c_{H}$ and $c_{L}$ with respect to $\mu$ in case of multiple retailers

In case of multiple retailers, the comparison between Figure 5 and Figure 6 reveals that the discount mechanism of platform discount for retailers to improve product quality cannot be fully effective, and there are two situations: incentive effect and incentive failure. Whether the incentive mechanism can take effect is affected by the unit costs ${ }^{c_{H}}$ and ${ }^{c_{L}}$ of high- and lowquality products. When $c_{H}$ is greater than the threshold value corresponding to each $c_{L}$ value, $\mu_{32}^{N^{*}}>\mu_{31}^{N^{*}}$, the platform discount increases the rate of high-quality products in the market, and then the incentive mechanism takes effect. On the contrary, when ${ }^{c_{H}}$ is less than the threshold value corresponding to each $c_{L}$ value, then $\mu_{31}^{N^{*}}>\mu_{32}^{N^{*}}$, the platform discount reduces the rate of high-quality products in the market, and the incentive mechanism fails at this time.

When given the value of unit $\operatorname{cost}^{c_{L}}$ of low-quality products, whether the platform offers discounts or not, the rate of high-quality products in the market will decrease with the increase of $c_{H}$. When $c_{H}$ is always lower than the threshold, the incentive mechanism can't take effect; when $c_{H}$ exceeds the threshold, the incentive mechanism starts to take effect, and with the increase of $c_{H}$, the discount incentive effect becomes more obvious.

And given the value of unit $\operatorname{cost}^{c_{H}}$ of high-quality products, whether the platform offers discounts or not, with the increase of $c_{L}$, that is, the smaller the difference between unit cost of high- and low-quality products provided by retailers, the higher the rate of high-quality 
products in the market.

\section{CONCLUSION}

In this study, from the perspective of online shopping platform that is willing to motivate retailers to improve product quality, the quality control problem of online shopping supply chain is discussed by analyzing the effectiveness of discount mechanism. The results show that when a single retailer provides products at a single quality level, whether the incentive mechanism of platform discount is effective depends on the platform's deposit strategy and the unit costs of the high- and low-quality products respectively. And when a single retailer provides products at multiple quality levels, the incentive mechanism of platform discount is completely effective, the price discount of platform has a positive incentive effect on retailers, online retailers increase the sales of high-quality products, reduce the sales of low-quality products, which improve the high-quality product rate in the market. Also, in the case of multiple retailers, the effectiveness of the platform discount incentive mechanism depends on the unit cost of two kinds of products.

Through numerical analysis, the impact of the change of relevant parameters on the effectiveness of platform discount incentive mechanism is further studied. The results show that when a single retailer provides products at a single quality level, the space for the incentive mechanism to take effect will increase with the increase of the required deposit, but the incentive mechanism is partially effective; when the deposit reaches a certain threshold, the incentive mechanism is fully effective. In the case of a single retailer providing products at multiple quality levels and multiple retailers, given the unit cost of low-quality products within a certain range, whether the platform provides discounts or not, the rate of high-quality products in the market will decrease with the increase of unit cost of high-quality products. And when given the unit cost of high-quality products, whether the platform offers discounts or not, with the increase of unit cost of low-quality products, that is, the smaller the difference between the unit cost of high-quality products and low-quality products provided by retailers, the higher the rate of high-quality products in the market.

In this study, the product quality control of retailers by a single platform e-commerce is discussed based on simple discount incentive strategy from the perspective of online shopping platforms. The situation of multiple platforms considering various charging factors of platforms can be studied to explore the incentive mechanism of product quality in more complex situations in the future. And further discussion about the incentive of platform autonomy are also necessary. 


\section{ACKNOWLEDGEMENTS}

This research was supported by National Natural Science Foundation of China (No.72003081), the Major Project of Philosophy and Social Science Research of Colleges and Universities in Jiangsu Province (2021SJZDA134) and the General Project of Philosophy and Social Science Research in Colleges and Universities in Jiangsu Province (No.2019SJA0759).

\section{REFERENCES}

[1] Resnick P, Kuwabara K, Zeckhauser R, et al (2000). Reputation systems. Communications of the ACM, 43(12): 45-48.

[2] Wang DW (2011). Mechanism design of position auction with advertiser reputation for Web-search. System Engineering - Theory and Practice, 31(01): 38-42.

[3] Kang WL, Wang L, Jiang YN (2016). Online trust transactions through an incentive mechanism based on trusted third party. Journal of Systems and Management, 25 (05): 821-828.

[4] Wang Y, Wang M, Huang GY. Can platform be big and nice - a study of firm's quality choice in different ranking mechanisms. China Industrial Economics, 2019 (04): 155-173.

[5] Zhao HX, Rong S, Yang JP. Research on the Behavior and Governance Mechanism of Cash Back for Favourable Comment Provided by Online Sellers and Consumers' Mercenary. China Economic Studies, 2017 (06): 110-121.

[6] Xu Y, Zhang Y, Yu C, et al (2018). Optimal control of an online reputation dynamic feedback incentive model. Communications in Nonlinear Science and Numerical Simulation, 63: 1-11.

[7] Zhang E, Yang F, Wang YL. Incentive mechanism for building trust in online market. Journal of Management Sciences in China, 2007 (01): 64-70.

[8] Raza SA (2018). Supply chain coordination under a revenue-sharing contract with corporate social responsibility and partial demand information. International Journal of Production Economics, 205: $1-14$.

[9] Hu B, Feng Y (2017). Optimization and coordination of supply chain with revenue sharing contracts and service requirement under supply and demand uncertainty. International Journal of Production Economics, 183: 185-193.

[10] Venegas BB, Ventura JA (2018). A two-stage supply chain coordination mechanism considering price sensitive demand and quantity discounts. European Journal of Operational Research, 264(2): 524-533.

[11] Nie T, Du S (2017). Dual-fairness supply chain with quantity discount contracts. European Journal of Operational Research, 258(2): 491-500.

[12] Zhang S, Meng QC, An GZ (2019). Coordinated pricing in the dual channel supply chain with the commission rate of the e-commerce platform. Chinese Journal of Management Science, 27(10): 4455.

[13] Sun BW, Li EL, Wang SJ, He Y, Li YY (2014). Design and implement of dynamic trading security deposit in reputation incentive mechanism for building trust in online trading market. Management Review, 26 (03): 31-38. 
[14] Gui Y, Gong B. Quality Assurance Competition Strategy under B2C Platform (2016). Discrete Dynamics in Nature and Society, 2016.

[15] Song H, Zhu CJ, Dai Y (2016). First-time transaction incentive mechanism considering incomplete trust under e-commerce environment without third party guarantee. Computer Integrated Manufacturing Systems, 22(04): 1155-1163.

[16] Gui YM, Gong BG, Cheng YH (2018). Research on quality assurance strategy for e-commerce platform considering bilateral effort. Chinese Journal of Management Science, 26(01): 163-169.

[17] Qin XH, Li HN, Cao YY (2020). Incentive contract design for online shopping service supply chains considering fair profit distribution in multi-servicers competition environment. Industrial Engineering and Management, 25(06): 144-153.

[18] Zhao D, Han H, Shang J, et al (2020). Decisions and coordination in a capacity sharing supply chain under fixed and quality-based transaction fee strategies. Computers \& Industrial Engineering, 150: 106841.

[19] Zhao HX, Li H, Wang L. Study on the quality integrity incentive of online platform to online seller based on advertising space allocation. Chinese Journal of Management Science, https://doi.org/10.16381/j.cnki.issn1003-207x.2019.0503. 